\title{
Analysis of Reasons for Extraction of Permanent Teeth in Children in Senegal: A Retrospective Study
}

\author{
Ndoye Soukeye*, Diallo M Tidiane, Diouf Abdoulaye, Diouf N Guignane, Faye Malick and Tamba Aissatou \\ Department of Pediatric Dentistry, Cheikh Anta Diop University, Africa \\ Received: 畊 September 10, 2018; Published: 㘹 October 01, 2018 \\ *Corresponding author: Soukeye Ndoye, Department of Pediatric Dentistry, Cheikh Anta Diop University, Africa
}

\begin{abstract}
Background: Loss of permanent teeth can have negative functional, psychological and social consequences, especially for children and adolescents with growing bone structures. Knowledge of their causes is of interest in the development of comprehensive dental public health programs. The objective of this study was to evaluate the reasons for extractions of permanent teeth in children in public oral structures in Dakar.
\end{abstract}

Material and method: A retrospective descriptive study, based on consultation registers and patient records, was performed. Patients between the ages of 6 and 15 who had permanent tooth extractions between January 2014 and August 2018 were included. A questionnaire including socio-demographic data, reason for consultation, reason for extraction and extracted teeth was included allowed to collect the data.

Results: A total of 321 patients aged 6 to 15 years received 375 permanent tooth extractions (1.16 teeth / child). Dental caries and its complications were the main reasons for extractions $(94.7 \%)$.

Conclusion: Dental caries remains a real public health problem in developing countries. Decision-makers need to focus on strategies for the prevention and management of early childhood oral conditions to avoid the extraction of permanent teeth.

Keywords: Reasons for Extraction; Permanent Teeth; Child, Tooth Decay; Senegal

\section{Introduction}

The extraction of permanent teeth should not be an insignificant act, especially in children, because of the negative repercussions on eruption phenomena, the harmony of the arches, the primary functions of chewing, swallowing, breathing and phonation. Indeed, the first permanent molar, which is the first permanent tooth to erupt, is the keystone of the occlusion; it determines the shape of the lower part of the face and conditions the position and health of the other permanent teeth [1]. The decision to extract permanent teeth must be reasoned and integrated into a global treatment plan that often requires collaboration with other dental specialties. The analysis of the causes of permanent tooth loss is of interest to practitioners and decision-makers in order to develop control strategies to be integrated into overall dental public health programs. It is from this perspective that an indirect method based on the search for reasons for these permanent tooth losses by extraction has been developed and used in many countries. Numerous studies on the causes of permanent tooth extraction in children, adolescents and adults have been conducted in industrialized countries [2-5] and caries and periodontal disease have been the main causes of extractions. In Africa, studies are rare. The main objective of this study was to evaluate the reasons for extractions of permanent teeth in children in public oral structures in Dakar.

\section{Materials and Methods}

This was a descriptive retrospective study of patients consulting the oral structures of Aristide Dantec Hospital (HALD), Albert Royer National Children's Hospital of Fann (CHNEAR), Dakar Institute of Odonto-Stomatology (IOS) and Grand Yoff General Hospital (HOGGY). Patient selection was based on consultation records. All records of patients aged 6 to 15 years who received permanent tooth extractions were included in the study. A "reasoned choice" sampling was conducted. A data sheet was 
used to collect information on socio-demographic data, the reason for consultation, the reasons for extraction, and the type of teeth extracted. The collected data were analysed with the SPSS 20.0 IBM software. The quantitative variables were described by their means and standard deviations. The qualitative variables were described by their numbers and percentages.

\section{Results}

Among 26362 children consulted, 321 patients (1.21\%) aged 6 to 15 years had received permanent tooth extractions. The number of permanent teeth extracted was 375 (1.16 teeth/child). Girls had received $55.2 \%$ of extractions. The number of permanent teeth extracted was 375 (1.16 teeth / child). Girls had received 55.2\% of extractions. The 12-15 age group had benefited from $77.88 \%$ (Table 1). The distribution of extractions by health centre was $33.64 \%$ in the CHNEAR and $31.77 \%$ in HOGGY (Table 2). The first molars accounted for $76.94 \%$ of the extracted teeth (Table 3). Dental caries and its complications were the main reasons for extracting permanent teeth in $94.16 \%$ of cases (Table 4). Pain was the reason for consultation for $74.8 \%$ of extracted teeth (Figure 1).

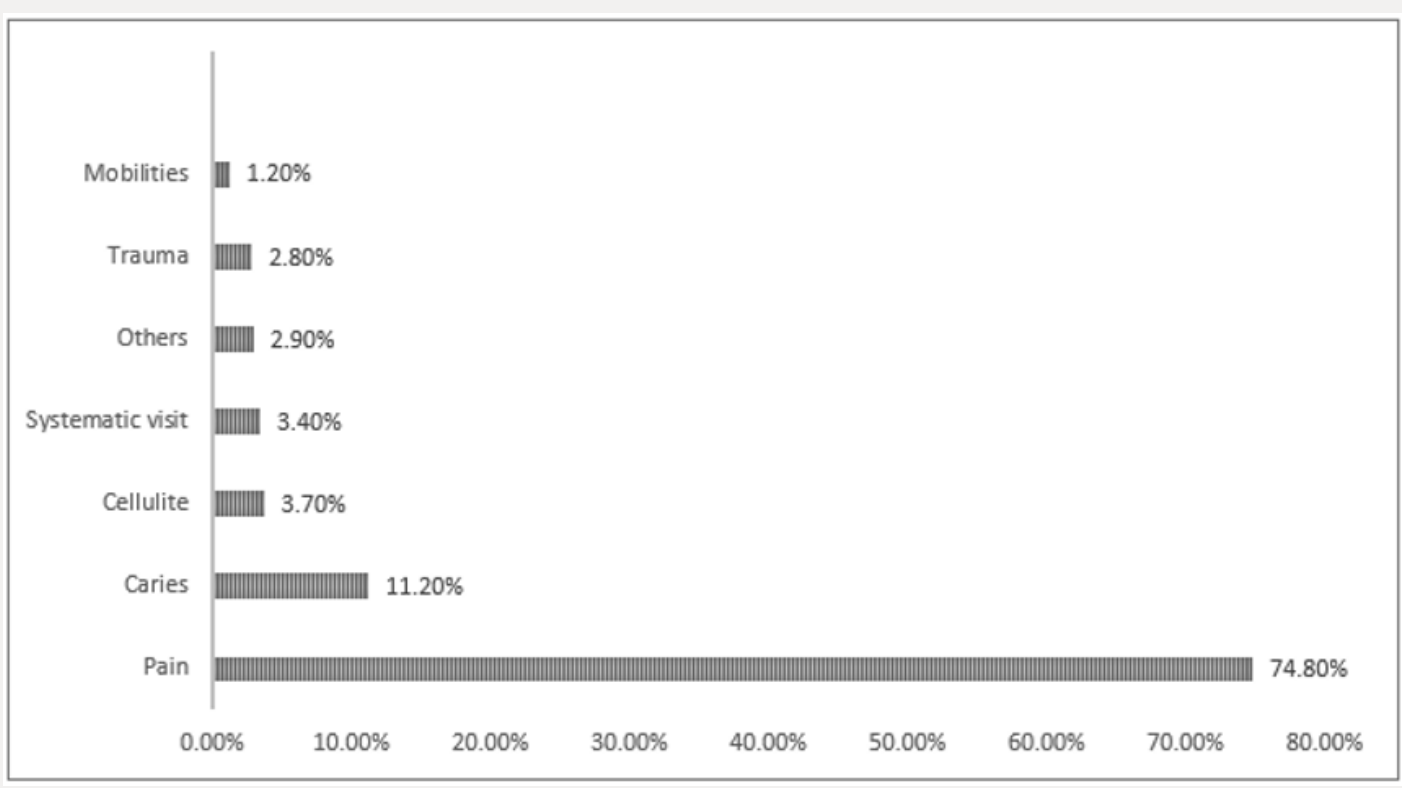

Figure 1: Breakdown by reasons for consultation.

Table 1: Distribution of extractions by age group.

\begin{tabular}{|c|c|c|c|}
\hline $\begin{array}{c}\text { Age group } \\
\text { (years) }\end{array}$ & {$[\mathbf{6 - 9 ]}$} & [9-12] & [12-15] \\
\hline Staff (\%) & 7,20 & 14,13 & 78,66 \\
\hline
\end{tabular}

Table 2: Distribution of extractions according to the host structure.

\begin{tabular}{|c|c|c|c|c|}
\hline $\begin{array}{c}\text { Health } \\
\text { Structure }\end{array}$ & CHNEAR & HOGGY & IOS & HALD \\
\hline Staff (\%) & 33,64 & 31,77 & 19,00 & 15,59 \\
\hline
\end{tabular}

Table 3: Distribution of extractions according to tooth type.

\begin{tabular}{|c|c|c|c|c|c|}
\hline $\begin{array}{c}\text { Tooth } \\
\text { Type }\end{array}$ & $\begin{array}{c}\text { First } \\
\text { Permanent } \\
\text { Molar }\end{array}$ & Premolar & $\begin{array}{c}\text { Second } \\
\text { Permanent } \\
\text { Molar }\end{array}$ & Incisor & Canine \\
\hline $\begin{array}{c}\text { Staff } \\
(\%)\end{array}$ & 76,94 & 9,60 & 8,66 & 3,20 & 1,60 \\
\hline
\end{tabular}

Table 4: Distribution by extraction reasons.

\begin{tabular}{|c|c|c|c|c|c|}
\hline $\begin{array}{c}\text { Reasons } \\
\text { for } \\
\text { Extract } \\
\text { ions }\end{array}$ & Caries & Orthodontic & Trauma & $\begin{array}{c}\text { Eruption } \\
\text { Accident }\end{array}$ & Aesthetic \\
\hline Staff (\%) & 94,66 & 1,86 & 1,59 & 1,36 & 0,53 \\
\hline
\end{tabular}

\section{Discussions}

The health structures selected in this study have the particularity of being centres receiving many patients for general health and oral health care. In addition, the CHNEAR and the IOS have services exclusively oriented towards the oral care of children and adolescents. The prevalence of permanent tooth extractions seems low but not negligible given the key role played by these teeth and in particular the first permanent molar. This result is lower than that reported by Murray et al [6] and Johansen et al [7]. This could be explained by the difference in the study population, which was made up of adults and elderly subjects (20-50 years and $>70$ years). Children in the $12-15$ age group received more extractions than others. This shows that the number of permanent teeth extracted increases with age. Pain was the main reason for consultation and concerned the majority of patients. Studies by several authors $[8,9]$ have produced similar results. This is linked to an economic situation and/or a lifestyle that is not compatible with a "preventive-conscious" approach. Difficulties in access to dental care, lack of dental facilities, lack of financial resources or lack of information and education on oral health may constitute a barrier to systematic visits or consultations as soon as the first signs of dental problems appear [10]. Dental caries and its complications were the 
most common reasons for extraction of permanent teeth. The first permanent molars were the most frequently extracted teeth. These data support the results of Shammari et al [11] who reported that dental caries was the leading cause of permanent tooth extractions in patients under 40 years of age and that the first permanent molars were the most affected teeth. Other studies [12-17] have shown that the first permanent molar was the most extracted tooth with prevalence ranging from $11.7 \%$ to $86.2 \%$. A study by Safadi et al [18] in subjects aged 13 to 20 years showed that the prevalence of extractions of the first permanent molars was $31.3 \%$, of which $76.5 \%$ concerned the first lower molars and that dental caries and its consequences were the main reasons for extraction. The greater susceptibility of the first molars to extraction can be explained by several factors. Their eruption, usually around 6 years of age, is silent and usually goes unnoticed, resulting in defective brushing. They have an occlusal surface whose morphology is more favourable to the retention of soft cariogenic deposits [19]. However, given their important roles, especially in children and adolescents, their extraction should be the ultimate therapeutic choice.

\section{Conclusion}

It should be noted that dental caries and its complications are the main reasons for the extraction of permanent teeth in children. It is important to implement a policy of promotion, prevention and early management of oral diseases in children aged 12 to 15 years in order to reduce dental loss.

\section{References}

1. (2006) Tooth eruption: the permanent teeth. The Journal of the American Dental Association 137: 127.

2. Cahen PM, Frank RM, Turlot JC (1985) A survey of the reasons for dental extractions in France. J Dent Res 64: 1087-1093.

3. Angelillo IF, Nobile CGA, Pavia M (1996) Survey of reasons for extraction of permanent teeth in Italy. Community Dent. Oral Epidemiol 24(5): 336-340.

4. Morita M, Kimura T, Kanegae M, Ishirawa A, Watanabe T (1994) Reasons for extraction of permanent teeth in Japan. Community Dent Oral Epidemiol 22: 303-306.
5. Haddad I, Haddadin K, Jebrin S, Ma Ani M, Yassin O (1999) Reasons for extraction of permanent teeth in Jordan. Int Dent J 49(6): 343-346.

6. Murray H, Locker D, Kay EJ (1996) Patterns of and reasons for tooth extractions in general dental practice in Ontario, Canada. Community Dent Oral Epidemiol 24(3): 196-200.

7. Johansen SB, Johansen JR (1997) A survey of causes of permanent tooth extractions in South Australia Aust Dent J 22(4): 238-242.

8. Dixit LP, Gurung CK, Gurung N, Joshi N (2010) Reasons underlying the extraction of permanent teeth in patients attending Peoples Dental College and Hospital. Nepal Med Coll J 12: 203-206.

9. Songo BF, Vinquier F, Pilipili C, Kayembe KP, Declerck D (2010) The patterns of Paediatric ondotology in Kinshasa, The Democratic Republic of Congo. In: Annals of African Medicine 3(4): 574-581.

10. Dieng SD, Cisse D, Lombrail P et al. (2016) Oral Health Status, Supply of Oral and Dental Care among Senegalese Children: A Review of Available Data. J Public health 28(2): 257-265.

11. Al-Shammari KF, Al-Ansari JM, Al-Melh MA, Al Khabbaz AK (2006) Reasons for tooth extraction in Kuwait. Medical Principles and Practice 15(6): 417-422.

12. Adeyemo WL, Oderinu HO, Oloseye SB, Taiwo OA, Akinwande JA (2008) Indications for extraction of permanent teeth in Nigerian teaching hospital: 16 year follow up study. Niq Q J Hosp Med 18(3): 128 -132.

13. Artun J, Thalib L (2011) Mesial migration and loss of first molars among young adolescents in Kuwait. Community Dental Health 28(2):154-159.

14. Saheeb BD, Sede MA (2013) Reasons and pattern of tooth mortality in a Nigerian Urban teaching hospital. Annals of African Medicine 12(2): 110-114.

15. Halicioglu K, Toptas O, Akkas I, Celikoglu M (2014) Permanent first molar extraction in adolescents and young adults and its effect on the development of third molar. Clinical Oral Investigations 18(5): 14891494.

16. Eigbobo JO, Gbujie DC, Onyeaso CO (2014) Causes and pattern of tooth extractions in children treated at the University of Port Harcourt Teaching Hospital. Odonto-stomatologie Trop 37(146): 35-41.

17. Alesia K, Khalil HS (2013) Reasons for and patterns relating to the extraction of permanent teeth in a subset of the Saudi population. Clinical, Cosmetic and Investigational Dentistry 5: 51-56.

18. Safadi Rahaf (2018) Prevalence of first permanent molar loss in a population of Saudi adolescents and young adults. International Journal of Emerging Trends in Science and Technology 5(4): 6577-6584.

19. Carvallo JC, Ekstrand KR, Thylstrup A (1989) Dental plaque and caries on occlusal surfaces of first permanent molars in relation to stage of eruption. J dent Res 68: 773-779.

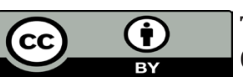

This work is licensed under Creative Commons Attribution 4.0 License

To Submit Your Article Click Here:

Submit Artic

DOI: $10.32474 /$ IPDOAJ.2018.02.000131

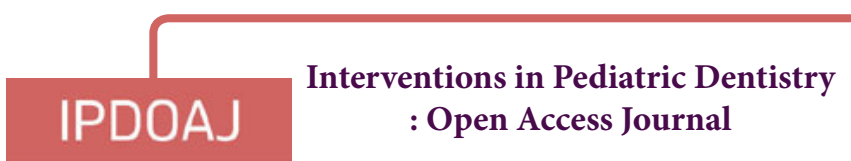

\section{Assets of Publishing with us}

- Global archiving of articles

- Immediate, unrestricted online access

- Rigorous Peer Review Process

- Authors Retain Copyrights

- Unique DOI for all articles 